\title{
Characterizing the bioburden of ESBL-producing organisms in a neonatal unit using chromogenic culture media: a feasible and efficient environmental sampling method
}

Moses Vurayai ${ }^{1 *+}$, Jonathan Strysko ${ }^{2,3,4+} \odot$, Kgomotso Kgomanyane ${ }^{5}$, One Bayani ${ }^{2}$, Margaret Mokomane ${ }^{1}$, Tichaona Machiya ${ }^{5}$, Tonya Arscott-Mills ${ }^{2,3,4}$, David M. Goldfarb ${ }^{6}$, Andrew P. Steenhoff 2,3,4,7, Carolyn McGann ${ }^{3,7}$, Britt Nakstad ${ }^{2,8}$, Alemayehu Gezmu ${ }^{2}$, Melissa Richard-Greenblatt ${ }^{7}$ and Susan Coffin ${ }^{3,7}$

\begin{abstract}
Introduction: Infections due to extended spectrum beta-lactamase producing organisms (ESBL) have emerged as the leading cause of sepsis among hospitalized neonates in Botswana and much of sub-Saharan Africa and south Asia. Yet, ESBL reservoirs and transmission dynamics within the neonatal intensive care unit (NICU) environment are not well-understood. This study aimed to assess the efficiency and feasibility of a chromogenic-culture-media-based environmental sampling approach to characterize the ESBL bioburden within a NICU.

Methods: A series of four point-prevalence surveys were conducted at a 36-bed NICU at a public tertiary referral hospital in Botswana from January-June 2021. Samples were collected on 4 occasions under semi-sterile technique using 1) flocked swabs \& templates (flat surfaces); 2) sterile syringe \& tubing (water aspiration); and 3) structured swabbing techniques (hands \& equipment). Swabs were transported in physiological saline-containing tubes, vortexed, and $10 \mu \mathrm{L}$ was inoculated onto chromogenic-agar that was selective and differential for ESBL (CHROMagar ${ }^{\mathrm{TM}}$ ESBL, Paris, France), and streaking plates to isolate individual colonies. Bacterial colonies were quantified and phenotypically characterized using biochemical identification tests.

Results: In total, 567 samples were collected, 248 (44\%) of which grew ESBL. Dense and consistent ESBL contamination was detected in and around sinks and certain high-touch surfaces, while transient contamination was demonstrated on medical equipment, caregivers/healthcare worker hands, insects, and feeding stations (including formula powder). Results were available within 24-72 h of collection. To collect, plate, and analyse 50 samples, we estimated a total expenditure of \$269.40 USD for materials and 13.5 cumulative work hours among all personnel.
\end{abstract}

Conclusions: Using basic environmental sampling and laboratory techniques aided by chromogenic culture media, we identified ESBL reservoirs (sinks) and plausible transmission vehicles (medical equipment, infant formula, hands of caregivers/healthcare workers, \& insects) in this NICU environment. This strategy was a simple and cost-efficient

\footnotetext{
*Correspondence: mvurayai@gmail.com

${ }^{\dagger}$ Moses Vurayai and Jonathan Strysko are co-first authors

${ }^{1}$ Department of Medical Laboratory Sciences, Faculty of Health Sciences,

University of Botswana, Gaborone, Botswana

Full list of author information is available at the end of the article
}

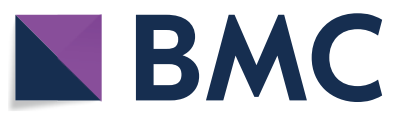

(c) The Author(s) 2022. Open Access This article is licensed under a Creative Commons Attribution 4.0 International License, which permits use, sharing, adaptation, distribution and reproduction in any medium or format, as long as you give appropriate credit to the original author(s) and the source, provide a link to the Creative Commons licence, and indicate if changes were made. The images or other third party material in this article are included in the article's Creative Commons licence, unless indicated otherwise in a credit line to the material. If material is not included in the article's Creative Commons licence and your intended use is not permitted by statutory regulation or exceeds the permitted use, you will need to obtain permission directly from the copyright holder. To view a copy of this licence, visit http://creativecommons.org/licenses/by/4.0/. The Creative Commons Public Domain Dedication waiver (http://creativeco mmons.org/publicdomain/zero/1.0/) applies to the data made available in this article, unless otherwise stated in a credit line to the data. 
method to assess ESBL bioburden and may be feasible for use in other settings to support ongoing infection control assessments and outbreak investigations.

Keywords: Neonatal sepsis, Extended-Spectrum-Beta-Lactamase, Enterobacterales, Pseudomonadales Klebsiella, Acinetobacter, Bioburden, Environmental sampling, Hand hygiene, Powdered Infant Formula, Infection control,

Chromogenic culture media

\section{Introduction}

In recent decades, infections due to multidrug resistant (MDR) enteric organisms have emerged as the leading causes of neonatal sepsis in sub-Saharan Africa and south Asia [1-3]. In Botswana, the most common causes of laboratory-confirmed bloodstream infection (BSI) among hospitalized neonates are Gram-negative bacteria, most commonly Klebsiella species [4]. Over $80 \%$ of neonatal bloodstream Klebsiella isolates in this setting are reported to be extended spectrum beta-lactamase producing ${ }^{1}[4]$. Carbapenem resistance is also emerging as a cause of neonatal sepsis in southern Africa $[5,6]$. Infections due to carbapenem-resistant and extended spectrum beta-lactamase producing organisms (ESBL) are difficult to treat and confer a high mortality risk in neonates; over one in three neonates with an ESBL bloodstream infection will die $[1,7]$.

Hyper-endemic rates of neonatal sepsis in sub-Saharan Africa and south Asia are thought to be driven by overcrowded neonatal wards, barriers to effective hand hygiene, equipment re-use, and limited laboratory capacity to detect and respond to outbreaks. Infection prevention efforts are often thwarted because the ecology and transmission dynamics of these organisms within the neonatal intensive care unit (NICU) are not well understood. Bacteria in the Enterobacterales (e.g. Klebsiella, Enterobacter spp.) and Pseudomonadales (e.g. Acinetobacter, Pseudomonas spp.) orders are well suited to survive in moist and warm settings and emerging data suggest that damp reservoirs within the hospital environment, such as sink drains, washbasins, and oxygen humidifiers, could contribute to the acquisition of ESBL among patients [8-10]. However, little is known about potential ESBL reservoirs specifically within NICUs and whether they contribute to neonatal colonization and disease.

Environmental surface sampling in healthcare facilities is warranted to identify reservoirs and vehicles for clinically important pathogens [11]. However, infection control teams in resource-limited settings often lack the conventional equipment (e.g. sponge sticks, extractors,

\footnotetext{
${ }^{1}$ For clinical reports from Botswana, extended-spectrum beta-lactamase production is inferred from extended-spectrum cephalosporin resistance detected on phenotypic antibiotic susceptibility testing.
}

etc.) and laboratory capacity to conduct a meaningful investigation. Moreover, environmental sampling data can be difficult to interpret and are often skewed toward recovery of Gram positive organisms with unclear clinical relevance [12].

Environmental sampling techniques can be classified based on: a) sampling device (e.g. swab vs. sponge), b) method of sample preparation (e.g. dry vs. pre-moistened), c) transport and storage method, and d) sample processing (e.g. extraction, enrichment, incubation) [13]. Techniques that seek to identify specific pathogens typically focus on demonstrating qualitative presence of organisms of interest, whereas quantitative data are needed to characterize microbial bioburden to target interventions to the reservoirs with the greatest burden of potentially pathogenic organisms [13]. Environmental sampling in NICUs has historically focused on qualitative identification of pathogens as part of an outbreak investigation or as part of specific quality assurance purposes [14]. Reports of persistent reservoirs (as opposed to transient contamination) for ESBL identified within a NICU are rare [15].

In this study, we aimed to assess the efficiency and feasibility of a chromogenic-culture-media-based environmental sampling approach using basic sample collection equipment in a NICU where infections with ESBL are hyper-endemic. By deploying this technique over time on a range of samples from water, surfaces, hands and equipment in the hospital environment, we aimed to characterize the ESBL bioburden, and identify reservoirs and vehicles, which could then be targets for remediation and disinfection.

\section{Methods}

\section{Study design}

This study consisted of a series of point prevalence surveys, which took place on four separate occasions from January-June 2021. It underwent ethical review and approval by the Health Research and Development Committee at Botswana's Ministry of Health and Wellness and the Institutional Review Boards at University of Botswana and the healthcare facility whether this study was carried out. 


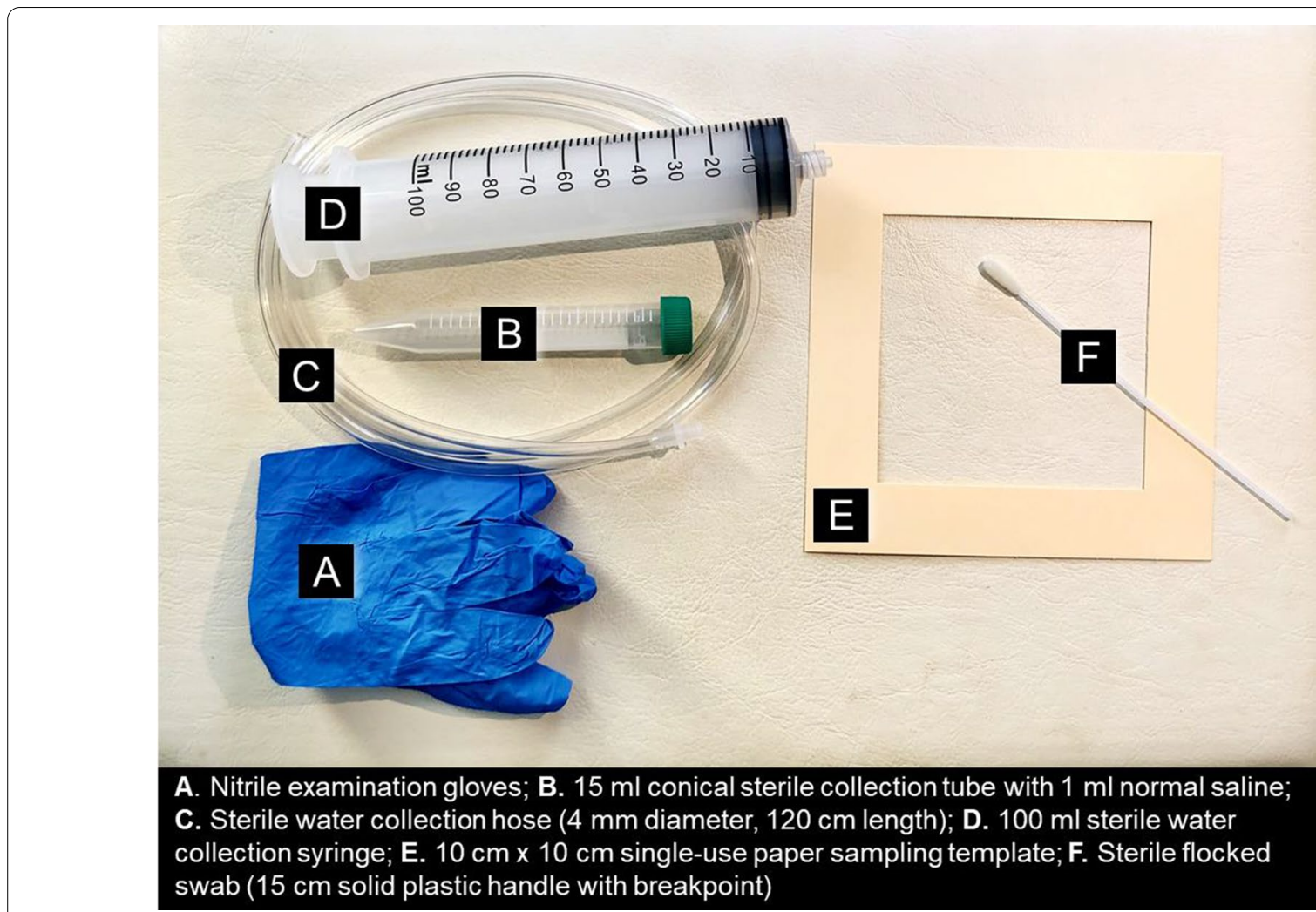

Fig. 1 Devices used for environmental sampling in the neonatal unit

\section{Study setting}

The study was conducted in a 36-bed NICU within a 530-bed public tertiary referral hospital in Botswana where over 8000 deliveries occur annually. The neonatal unit is a one-storey block covering a total of 315 square meters, of which 87 square meters are patient care areas (average of $2.5 \mathrm{~m}^{2}$ per patient-mother dyad). The most common diagnoses among patients in this NICU are prematurity-related complications, hypoxiarelated injuries, and sepsis. Neonatal care is provided by approximately 16 healthcare workers per day shift, 4-6 of whom are nurses. Neonatal care includes: oxygen/ventilatory support, cardio-respiratory monitoring, enteral and parenteral nutrition, thermoregulation, transfusion, post-surgical care, phototherapy, and fluid/ electrolyte management. Because of the shortage of staff, enteral feeding (both oral and gavage) is administered primarily by caregivers (mainly mothers). The unit's doors and windows open directly outdoors, which episodically results in entrance by flies and cockroaches, and has prompted the use of Light Emitting Diode (LED) insect traps.

\section{Environmental sampling technique}

\section{a. Sampling devices}

We used sampling equipment that was relatively inexpensive and easy to source using local vendors in our setting (Fig. 1). This included: $15 \mathrm{~cm}$ sterile nylon flocked swabs with solid plastic handle and breakpoint (Puritan ${ }^{\circledR}$; Cat. No. 25-3406-U, a $10 \mathrm{~cm} \times 10 \mathrm{~cm}$ paper single-use paper sampling template for flat surface sampling (Environmental Express $^{\circledR}$; Cat. No. EE-C1010), $15 \mathrm{ml}$ plastic conical centrifuge tubes (SPL Life Sciences; Cat. No. 51015) for water samples and for transport of flocked swab samples, a $100 \mathrm{ml}$ sterile syringe and tubing (CareJoy, Cat. No. 784121) for water aspiration, and nitrile or latex examination gloves for the person collecting the sample.

\section{b. Sample preparation \& transport}

Prior to sample collection, flocked swabs were premoistened with $1 \mathrm{ml}$ of sterile normal saline at room temperature which had been inoculated into the conical tubes. After sample collection, water samples and flocked swab samples were placed in the conical tubes and transported in an ice pack and cooler 


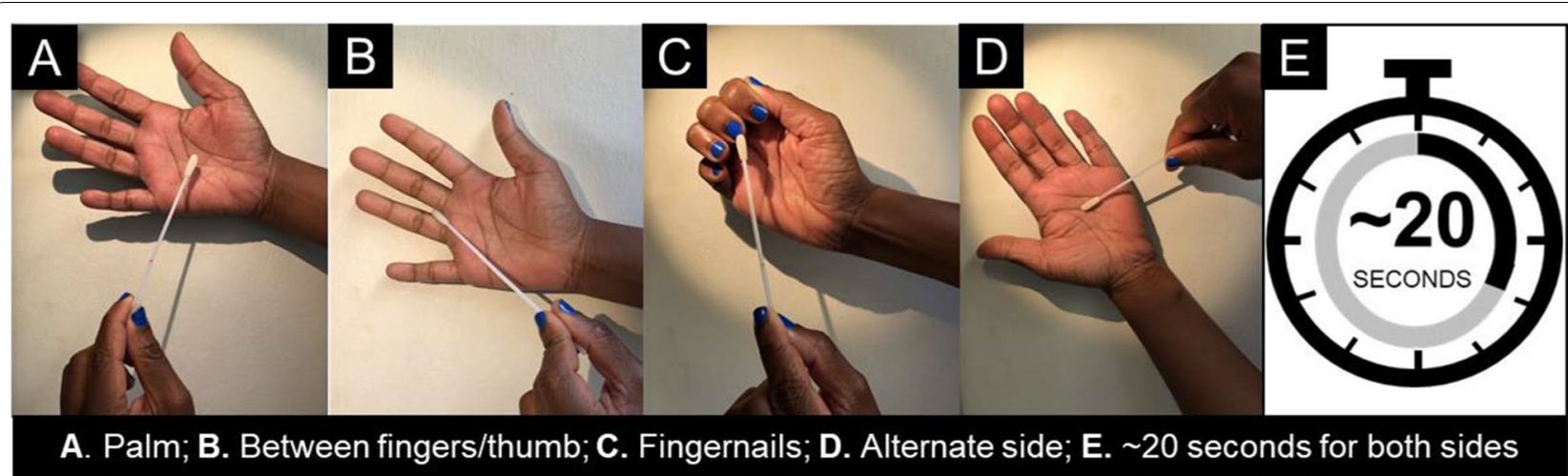

Fig. 2 Hand self-swab technique used by caregivers and healthcare workers

box to the laboratory, kept at $4^{\circ}$ degrees Celsius until being processed within 24-48 h.

c. Sample collection technique

\section{i. Water}

Free-flow water samples were collected directly from taps after allowing water to run for $5 \mathrm{~s}$. Water samples taken from plumbing traps were obtained by inserting a $4 \mathrm{~mm}$ diameter sterile plastic hose (alternatively, a naso-gastric tube can also be used) into the sink grid and water aspirated into a $100 \mathrm{ml}$ sterile syringe (smaller syringes can also be used).

\section{ii. Flat surfaces}

A $10 \mathrm{~cm} \times 10 \mathrm{~cm}$ single-use paper sampling template was placed on a flat surface and a pre-moistened flocked swab was streaked in a zigzag motion in three different orientations, rotating the swab while streaking for a total of $20 \mathrm{~s}$.

iii. Non-flat surfaces

A pre-moistened flocked swab was streaked in a zigzag motion in and around the non-flat surface, rotating the swab while streaking for a total of $20 \mathrm{~s}$.

iv. Infant formula

A pre-moistened, sterile flocked swab was stirred into an opened powered infant formula tin for approximately five seconds and placed into a conical tube.

v. Trapped insects

Insects were trapped in the immediate patient care environment using an LED light insect trap already in use in the unit to control insects. Insect corpses were lifted into the conical tubes using flocked swabs.

vi. Hands
Voluntary, anonymous swabbing of hands of healthcare workers and caregivers was carried out during three of the four sampling events. Healthcare workers and caregivers were asked to self-swab their hands using a standard technique illustrated in Fig. 2 prior to washing their hands with soap, water, and then drying and sanitizing with an alcohol-based hand rub (ABHR). Hand swabs were taken in the same manner after handwashing. In this neonatal unit where, prior to the Corona Virus Disease 2019 (COVID-19) pandemic, ABHR was not always available, handwashing upon entry to the unit using soap and water is enforced per hospital infection control guidelines. However, per World Health Organisation Guidelines on Hand Hygiene in Health Care, all hand hygiene should be performed using ABHR; the soapand-water method should be employed only when hands are visibly soiled or after using the toilet.[16].

\section{d. Sites sampled}

We sampled a combination of water, high-touch surfaces, infant formula, medical equipment, and trapped insects recovered from the immediate patient care area (Fig. 3). The same sites were sampled on all four occasions, however some sampling sites were added and removed as the sampling strategy was refined over time, and thus not all sites have four sampling results.

\section{e. Sample processing and culturing}

Swabs and saline-containing tubes were shaken on a vortex mixer to elute the sampled organisms and directly inoculated onto chromogenic-agar-media (CHROMagar ${ }^{\mathrm{TM}}$ ESBL, Paris, France), which is selective and differential for ESBL, using a $10 \mu \mathrm{L}$ graduated inoculating loop, streaking the plates to isolate 


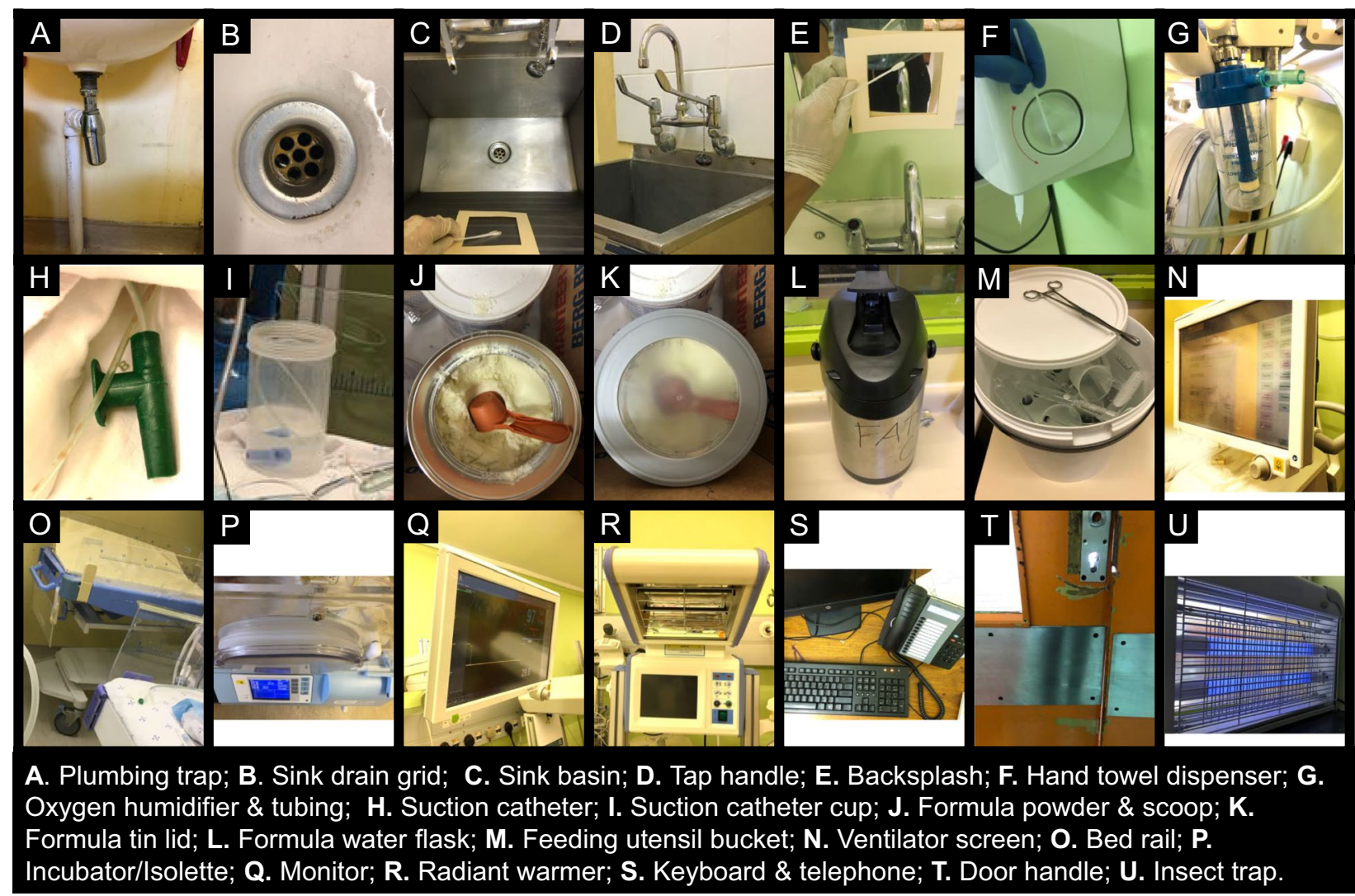

Fig. 3 Sites sampled during environmental sampling in the neonatal unit

individual colonies. Bacterial colonies were quantified and phenotypically characterized using biochemical identification tests. No growth was defined as growth of $<10$ colony-forming units (CFUs); light bacterial growth was defined as growth of $10-100$ CFUs, growth of $>100-<1000$ CFUs was considered moderate growth, and $>1000$ CFUs was considered heavy growth. For flat surfaces, bacterial growth was categorized using these CFU breakpoints per 100 $\mathrm{cm}^{2}$.

\section{f. Data analysis}

Data were analysed using basic descriptive statistics: crude numbers and frequencies using Microsoft Excel Software.

\section{Results}

In total, 567 samples were collected, 248 (44\%) of which grew ESBL, including species Klebsiella spp., Acinetobacter spp., Pseudomonas spp., Enterobacter spp., Citrobacter spp., and Escherichia coli.

\section{a. Results from environmental samples}

Dense and consistent ESBL contamination was detected inside plumbing traps, sink drain grids, and sink basins at all locations within the unit during all four sampling events (Fig. 4). Contamination was also consistently observed in certain high-touch surfaces (telephones, door handles, keyboards), while contamination was intermittently demonstrated on medical equipment (suction catheters, feeding tubes, and oxygen humidifiers) and feeding stations (including formula powder). Free-flow samples from tap water consistently demonstrated no growth.

\section{b. Results from hand swabs}

Hand contamination rates were higher among caregivers than among healthcare workers (Table 1). The most commonly identified organisms recovered from hands of healthcare workers were Pseudomonas spp., accounting for $42 \%$ of isolates recovered, followed by Acinetobacter spp. (30\%), Klebsiella spp. (15\%), Enterobacter spp. (12\%), and E.coli (4\%). Among caregivers, the most commonly identified organisms recovered from hand cultures were Klebsiella spp. (38\%), Acinetobacter spp. (38\%), Enterobacter spp. (11\%), Pseudomonas spp. (9\%), and E. coli (4\%). Microbial 


\begin{tabular}{|c|c|c|c|c|c|c|c|c|c|c|c|c|c|c|c|}
\hline \multicolumn{5}{|c|}{ Washing stations } & \multicolumn{5}{|c|}{ High Touch Surfaces } & \multicolumn{2}{|c|}{ Medical Equipment } & \multicolumn{4}{|c|}{ \& Feeding stations } \\
\hline Sampling event \# & 1 & 2 & 3 & 4 & Sampling event \# & 1 & 2 & 3 & 4 & Sampling event \# & & 1 & 2 & 3 & 4 \\
\hline \multicolumn{16}{|c|}{ Entrance } \\
\hline Tap water sample & NG & NG & NG & NG & Door handle & $P$ & $\mathrm{P}$ & NG & $\mathrm{K}$ & \multicolumn{2}{|l|}{ Powdered formula 1} & & NG & NG & NG \\
\hline Plumbing trap & KPE & $\mathrm{P}$ & $\mathrm{KP}$ & $\mathrm{KA}$ & Countertop $\dagger$ & $\mathrm{KP}$ & $P$ & $\mathrm{~K}$ & NG & \multicolumn{2}{|l|}{ Powdered formula 2} & - & E A & NG & NG \\
\hline Sink drain grid & KPE & E & $\mathrm{KP}$ & $\mathrm{KA}$ & Telephone 1 & $\mathrm{KP}$ & $\mathrm{P}$ & $\mathrm{K}$ & NG & \multicolumn{2}{|l|}{ Formula scoop 1} & - & NG & NG & NG \\
\hline Sink basin $†$ & $\mathrm{P}$ & $\mathrm{PE}$ & KPA & $\mathrm{KA}$ & Telephone 2 & $\mathrm{KP}$ & $\mathrm{K}$ & $\mathrm{KA}$ & $\mathrm{K}$ & \multicolumn{2}{|l|}{ Formula scoop 2} & & $P$ & NG & NG \\
\hline Tap handle & $\mathrm{P}$ & - & $\mathrm{P}$ & NG & Waiting bench $\uparrow$ & $\mathrm{KP}$ & - & - & - & \multicolumn{2}{|l|}{ Formula lid 1} & & EA & - & NG \\
\hline Backsplash $†$ & - & $\mathrm{E}$ & NG & NG & Mobile phone & - & $\mathrm{P}$ & $\mathrm{K}$ & NG & \multirow{2}{*}{\multicolumn{2}{|c|}{ Formula lid 2}} & - & EA & $\mathrm{E}$ & NG \\
\hline Hand towel dispenser & $\mathrm{KP}$ & $\mathrm{E}$ & $\mathrm{K}$ & NG & Keyboard & KPE & - & $\mathrm{P}$ & $\mathrm{K}$ & & & & & & \\
\hline \multicolumn{16}{|c|}{ Unit A } \\
\hline Tap water sample & NG & NG & - & NG & Desk† & NG & NG & NG & NG & \multicolumn{2}{|l|}{ Oxygen humidifier* } & NG & - & - & NG \\
\hline Plumbing trap & $K P$ & $\mathrm{P}$ & KA & $\mathrm{K}$ & Monitor touch screens ${ }^{*} \dagger$ & NG & $\mathrm{P}$ & - & NG & \multicolumn{2}{|l|}{ Suction catheter* } & - & KEA & NG & $\mathrm{K}$ \\
\hline Sink drain grid & KP & $\mathrm{P}$ & $\mathrm{P}$ & A & Radiant warmers* $\dagger$ & NG $\mathrm{F}$ & $P E A$ & NG & NG & \multirow{2}{*}{\multicolumn{2}{|c|}{ Suction catheter cup* }} & NG & - & NG & $\mathrm{KA}$ \\
\hline Sink basin† & $K P$ & $\mathrm{P}$ & KPA & A & Bed rails*† & NG & NG & - & NG & & & - & PA & - & $\mathrm{K}$ \\
\hline Tap handle & $\mathrm{P}$ & - & $\mathrm{P}$ & NG & Ventilator touch screens ${ }^{*} \dagger$ & NG & - & - & NG & \multicolumn{2}{|c|}{ Portable suction machine } & $K P$ & - & A & KA \\
\hline Backsplash† & - & $P E$ & - & NG & Trapped insect (fruit fly) & - & E & KA & - & \multirow{2}{*}{\multicolumn{2}{|c|}{$\begin{array}{l}\text { Formula water flask } \\
\text { Feeding utensil bucket† }\end{array}$}} & NG & NG & $\mathrm{K}$ & NG \\
\hline Hand towel dispenser & NG & $\mathrm{P}$ & NG & NG & Trapped insect (cockroach) & - & $\mathrm{P}$ & - & - & & & NG & NG & NG & NG \\
\hline \multicolumn{16}{|c|}{ Unit B } \\
\hline Tap water sample & NG & NG & - & NG & Countertop & NG & NG & NG & NG & \multirow{7}{*}{\multicolumn{2}{|c|}{$\begin{array}{l}\text { Oxygen humidifier } \\
\text { Feeding utensil bucket† } \\
\text { Formula water flask }\end{array}$}} & NG & - & - & $\mathrm{K}$ \\
\hline Plumbing trap & $K P$ & - & $\mathrm{P}$ & - & Bed rails* $\dagger$ & $\mathrm{K}$ & NG & $\mathrm{K}$ & $\mathrm{K}$ & & & NG & NG & NG & NG \\
\hline Sink drain grid & $\mathrm{KP}$ & PA & $\mathrm{PC}$ & PK & & & & & & & & - & - & NG & NG \\
\hline Sink basin† & $K P$ & $P E$ & $\mathrm{P}$ & NG & & & & & & & & & & & \\
\hline Tap handle & $\mathrm{KP}$ & - & C & NG & & & & & & & & & & & \\
\hline Backsplash $†$ & - & $P$ & NG & NG & & & & & & & & & & & \\
\hline Hand towel dispenser & NG & A & NG & NG & & & & & & & & & & & \\
\hline \multicolumn{16}{|c|}{ Unit C } \\
\hline ter sample & NG & NG & - & NG & Countertop & NG & NG & $\mathrm{KA}$ & $\mathrm{K}$ & \multirow{2}{*}{\multicolumn{2}{|c|}{$\begin{array}{l}\text { Oxygen humidifier } \\
\text { Feeding utensil bucket } †\end{array}$}} & NG & - & - & $\mathrm{K}$ \\
\hline Plumbing trap & $P E$ & $\mathrm{PE}$ & KA & A & Bed rails* $\dagger$ & NG & 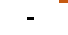 & - & NG & & & $\mathrm{P}$ & NG & NG & NG \\
\hline Sink drain grid & $K P$ & - & PA & NG & & & & & & \multirow{4}{*}{\multicolumn{2}{|c|}{ Formula water flask }} & - & - & NG & NG \\
\hline Sink basin† & $K P$ & - & PA & $\mathrm{KA}$ & & & & & & & & & & & \\
\hline Tap handle & KP & - & NG & NG & & & & & & & & & & & \\
\hline $\begin{array}{l}\text { Backsplash } \dagger \\
\text { Hand towel dispenser }\end{array}$ & NG & A & $\begin{array}{l}\text { NG } \\
\text { NG }\end{array}$ & $\begin{array}{c}\mathrm{NG} \\
\mathrm{K}\end{array}$ & & & & & & & & & & & \\
\hline & & & edicatio & on $\mathrm{Pr}$ & reparation Room & & & & & 10-100 CFU & $\mathrm{K}=\mathrm{Klel}$ & siella s & spp. & & \\
\hline Tap water sample & NG & - & - & NG & Fridge handle & $\mathrm{P}$ & NG & $\mathrm{K}$ & NG & $\begin{array}{l}>100-1000 \mathrm{CFU} \\
>1000 \mathrm{CFU}\end{array}$ & & romor & $\begin{array}{l}\text { nas spp. } \\
\text { ter spp. }\end{array}$ & & \\
\hline Plumbing trap & $K P$ & - & $\mathrm{P}$ & P K & Countertop & NG & & NG & $\mathrm{K}$ & Washing station & $\mathrm{A}=A c i$ & etobact & ter spp. & & \\
\hline Sink drain grid & $P E$ & A & $\mathrm{P}$ & $\mathrm{P}$ & Stethoscope & - & - & $\mathrm{K}$ & - & High-Touch Surface & $\mathrm{C}=$ Citr & bacter & spp. & & \\
\hline Sink basin $†$ & $P E$ & $P$ & PA & $\mathrm{PK}$ & & & & & & $\begin{array}{l}\text { Medical Equipment } \\
\text { Insects }\end{array}$ & $\begin{aligned} N G & =\text { No } \\
* & =\text { Cor }\end{aligned}$ & & esults & & \\
\hline Tap handle & KPE & - & - & $N G$ & & & & & & Feeding Stations & $t=$ Flat & surface & e; CFUs & $1100 \mathrm{c}$ & $\mathrm{cm} 2$ \\
\hline
\end{tabular}

Fig. 4 Contamination by extended-spectrum beta-lactamase producing organisms, by location, sample type, sampling event

Table 1 ESBL contamination of hands pre- and post-handwashing, by healthcare worker or caregiver, and sampling event

\begin{tabular}{llll}
\hline & Sampling event \#1 & Sampling event \#2 & Sampling event \#3 \\
\hline $\begin{array}{l}\text { Healthcare worker hands } \\
\text { Pre-wash contaminated }\end{array}$ & $29 \%(7 / 24)$ & $40 \%(2 / 5)$ & $45 \%(5 / 11)$ \\
Post-wash contaminated & $38 \%(9 / 24)^{*}$ & $20 \%(1 / 5)$ & $18 \%(2 / 11)$ \\
Caregiver hands & & & $63 \%(5 / 8)$ \\
Pre-wash contaminated & $85 \%(11 / 13)$ & $55 \%(11 / 20)$ & $38 \%(3 / 8)$ \\
Post-wash contaminated & $55 \%(6 / 11)^{\dagger}$ & $53 \%(8 / 15)^{\dagger}$ & \\
\hline
\end{tabular}

* Contamination among healthcare workers increased during the first sampling event, with Pseudomonas spp. accounting for most post-wash cultures

† Some participants were lost to follow-up to obtain post-wash swabs

contamination declined during all sampling events after washing, except among healthcare workers during the first sampling event, when contamination increased from 29 to $38 \%$ after washing, with most hands testing positive for Pseudomonas spp. Follow- ing these results, all participants were instructed to use ABHR following washing with soap and water. Of note, bacterial genera were recovered with roughly equal distribution over time, with the exception of Acinetobacter spp., which was not recovered 
at all during the first sampling event in January, but from 16 and 21 diverse sampling sites during the 2nd and 3rd sampling events. The third sampling event corresponded with an increase in Acinetobacter infections hospital wide, as per microbiological blood culture surveillance.

\section{c. Feasibility and Efficiency Assessment}

Most supplies were sourced using local vendors. To collect specimens, plate, and analyse 50 samples, we estimated a total expenditure of $\$ 269.40$ United States Dollars and 13.5 cumulative work hours among all personnel. Culture results were available within 24-72 h of collection. Although these results were analysed by a clinical microbiologist, the processing and culturing techniques were deemed to be appropriate for the level of a microbiology lab technician.

\section{Discussion}

Using basic environmental sampling and laboratory techniques aided by chromogenic culture media, we identified ESBL reservoirs (sinks) and plausible transmission vehicles (medical equipment, infant formula, hands of caregivers/healthcare workers, insects) in this NICU environment. This strategy was a simple and cost-efficient method to assess ESBL bioburden and may be feasible for use in other settings to support ongoing infection control assessments and outbreak investigations.

The identification of sinks as stable reservoirs for ESBL in this setting was anticipated; the moist and warm environments created by plumbing traps provide ideal conditions for biofilm formation [17]. Furthermore, eradication of ESBL from plumbing traps using conventional remediation techniques is challenging and therefore allows for long-term survival of bacterial communities [18]. Additionally, the stable contamination of sink grids, basins, tap handles, and some backsplashes demonstrated in this study illustrates the retrograde model of bacterial dispersal from wastewater previously postulated by in situ studies [17]. The fact that some healthcare workers' hands demonstrated Pseudomonas spp. post-handwashing which were not present prior to handwashing is concerning for acquisition from the sink environment (although could be explained by variability of swab technique). Following these results, the importance of using ABHR for all hand hygiene (including after washing with soap and water) was re-emphasized to all staff and caregivers.

The recognition of sinks as environmental reservoirs for ESBL has led some intensive care units (ICUs) to adopt "water free" care, moving sinks away from the immediate patient care environment, with corresponding declines in patient colonization rates for pathogens of interest [19]. In settings where these changes may not be feasible, interim measures targeting transmission vehicles are appropriate. In this study, we identified medical equipment, formula, insects, and hands of healthcare workers and caregivers as potential transmission vehicles that might move pathogenic organisms from a fixed location to the patient. Infection control teams should engage with doctors, nurses, and cleaning staff to ensure shared medical equipment is adequately disinfected in between uses, according to equipment package inserts or best practices, such as the U.S. Centers for Disease Control and Prevention's "Environmental Cleaning in Healthcare Facilities in ResourceLimited Settings" [20]. Preparation of shared powdered infant formula sources should be carefully monitored and, if possible, carried out in accordance with World Health Organisation's guidelines for safe preparation, storage and handling of powdered infant formula [21].

We found that insects within the patient care environment were often colonized with potentially pathogenic organisms. While insect infestations are not typically reported as contributing to either endemic or outbreaks of healthcare-associated infections, the importance of vector control in the patient care environment cannot be over-emphasized. For example, cockroaches have been implicated in outbreaks of neonatal K. pneumoniae infections [22], and ESBL colonization of fruit flies is welldocumented [23]. In our study setting, LED-light insect traps have proved to be an effective measure, along with window screens, at reducing the presence of insects in the patient care environment.

There are several limitations to this study, both in its technical and conceptual approach. First, environmental sampling was conducted at a single centre, and findings may not be generalizable to other units, depending on local climate, patient census, and cleaning practices. These point prevalence surveys were conducted in a ward that was actively used for patient care and the timing of sample collection had to adjust to the demands of patient care. Our sampling events were not coordinated with cleaning times, so we are unable to determine the extent to which current cleaning practices were effective in reducing the burden of contamination. We attempted to overcome this limitation by performing multiple sampling events and categorizing single contaminations as "transient" and repeated contaminations as "stable". Our use of "semi-sterile" techniques could have resulted in some false-positive results due to inadvertent contamination, but again we sought to counteract these limitations through the use of serial sampling. Although the chromogenic media chosen purports inhibition of all nonESBLs, including those producing ampC beta lactamases, the possibility of false positive results have been noted by other studies [24]. Thus, an overestimation of ESBL 
bioburden remains until isolates are confirmed using standard antimicrobial sensitivity methods.

Sampling bias may have influenced our findings on the prevalence of hand carriage of potential pathogens by caregivers and healthcare workers. For example, those confident with their hand hygiene practices may have been more willing to participate, leading to an underestimation of the true contamination rate.

This study took place in the midst of the COVID-19 pandemic, when heightened efforts to mitigate hospital transmission of Severe Acute Respiratory Syndrome Coronavirus-2 (SARS-CoV-2) were in place. In comparison to pre-pandemic practices, hand hygiene was enforced more strictly and soap and ABHR were more readily available. These important measures may have contributed to an overall decreased bacterial bioburden, particularly on the hands of healthcare workers and caregivers.

We are unable to confirm that the identified environmental contamination contributed to concurrent clinical infections. In future studies, whole genome sequencing can help to establish true transmission pathways.

Despite these limitations, this simple environmental sampling technique might be a feasible way in which neonatal and other high-risk units facing hyper-endemic rates of ESBL infections can better understand the nature of contamination and transmission dynamics in their unit. Further, it might help catalyse the implementation of infection control measures targeting defined reservoirs and suspected transmission pathways. The temporal link between increased recovery of Acinetobacter spp. from the environment and increased incidence of Acinetobacter infections hospital-wide is an anecdote of the importance of timely and reliable environmental sampling as an important outbreak response tool. This sampling method may also be pivotal in trialling and measuring the impact of novel remediation and prevention strategies. For example, neonatal units who have identified sinks as stable ESBL reservoirs should consider removing sinks and implementing "water-free" care for ICU patients [19], placing sink covers [25], or implementing anti-microbial alloys, such as copper, which has been shown to reduce microbial burden in NICUs [26]. This environmental sampling technique can be used to test microbial burden before and after implementation of these infection control interventions and track bioburden overtime.

\section{Conclusion}

In conclusion, basic environmental sampling and laboratory techniques aided by chromogenic culture media are sufficient to identify ESBL reservoirs and transmission vehicles and may be used in similar settings to support ongoing infection control assessments and outbreak investigations. More research is needed to understand the role of the environment in influencing risk of ESBL colonization and disease in neonates.

\section{Abbreviations \\ ABHR: Alcohol-Based Hand Rub; COVID-19: Corona Virus Disease 2019; CFU: Colony-forming units; ESBL: Extended-Spectrum Beta-Lactamase Produc- ing Organism; ICU: Intensive Care Unit; LED: Light Emitting Diode; NICU: Neonatal Intensive Care Unit; SARS-CoV-2: Severe Acute Respiratory Syndrome Coronavirus-2.}

\section{Acknowledgements}

This publication was made possible through core services and support from the Penn Center for AIDS Research (CFAR), an NIH-funded program (P30 Al 045008).

\section{Authors' contributions}

$\mathrm{MV}$ and JS contributed equally to this study as lead investigators. MV, JS, and KK conducted environmental sampling. SC, DG, AS, TAM, MM, TM, MRG, JS, and MV contributed to the conceptual development of sample collection and laboratory methods. MV performed the majority of laboratory analyses. JS and $\mathrm{SC}$ were major contributors to writing the manuscript. $\mathrm{AG}, \mathrm{BN}, \mathrm{OB}$, and $\mathrm{CM}$ contributed to the interpretation and presentation of data. All authors read and approved the final manuscript.

\section{Funding}

This study received funding from the Children's Hospital of Philadelphia Global Health Pilot Grant.

\section{Availability of data and materials}

All data generated or analysed during this study are included in this published article.

\section{Declarations}

Ethics approval and consent to participate

This study underwent ethical review and approval by the Human Research and Development Committee at Botswana's Ministry of Health and Wellness and the Institutional Review Board at University of Botswana.

\section{Consent for publication}

Not applicable.

\section{Competing interests}

The authors declare that they have no competing interests.

\section{Author details}

${ }^{1}$ Department of Medical Laboratory Sciences, Faculty of Health Sciences, University of Botswana, Gaborone, Botswana. ${ }^{2}$ Department of Paediatric \& Adolescent Health, Faculty of Health Sciences, University of Botswana, Gaborone, Botswana. ${ }^{3}$ Global Health Center, Children's Hospital of Philadelphia, Philadelphia, USA. ${ }^{4}$ Botswana-UPenn Partnership, Gaborone, Botswana. ${ }^{5}$ Ministry of Health and Wellness, Gaborone, Botswana. ${ }^{6}$ Department of Pathology and Laboratory Medicine, University of British Columbia, Vancouver, Canada. ${ }^{7}$ Perelman School of Medicine, University of Pennsylvania, Philadelphia, USA. ${ }^{8}$ Division of Paediatric and Adolescent Medicine, Institute of Clinical Medicine, University of Oslo, Oslo, Norway.

Received: 31 July 2021 Accepted: 5 December 2021

Published online: 24 January 2022

\section{References}

1. Flokas ME, Karanika S, Alevizakos M, Mylonakis E. Prevalence of ESBLproducing enterobacteriaceae in pediatric bloodstream infections: a systematic review and meta-analysis. PLoS ONE. 2017;12(1):e0171216. 
2. Chaurasia S, Sivanandan S, Agarwal R, Ellis S, Sharland M, Sankar MJ. Neonatal sepsis in South Asia: huge burden and spiralling antimicrobial resistance. BMJ. 2019:364:k5314.

3. Sands K, Carvalho MJ, Portal E, Thomson K, Dyer C, Akpulu C, et al. Characterization of antimicrobial-resistant Gram-negative bacteria that cause neonatal sepsis in seven low- and middle-income countries. Nat Microbiol. 2021;6(4):512-23.

4. Gezmu AM, Bulabula ANH, Dramowski A, Bekker A, Aucamp M, Souda S, et al. Laboratory-confirmed bloodstream infections in two large neonatal units in sub-Saharan Africa. Int J Infect Dis. 2020;103:201-7.

5. Reddy K, Bekker A, Whitelaw AC, Esterhuizen TM, Dramowski A. A retrospective analysis of pathogen profile, antimicrobial resistance and mortality in neonatal hospital-acquired bloodstream infections from 2009-2018 at Tygerberg Hospital, South Africa. PLoS ONE. 2021;16(1):e0245089.

6. Mpinda-Joseph P, Anand Paramadhas BD, Reyes G, Maruatona MB, Chise M, Monokwane-Thupiso BB, et al. Healthcare-associated infections including neonatal bloodstream infections in a leading tertiary hospital in Botswana. Hosp Pract. 1995:2019:1-8.

7. Ballot DE, Bandini R, Nana T, Bosman N, Thomas T, Davies VA, et al. A review of -multidrug-resistant Enterobacteriaceae in a neonatal unit in Johannesburg, South Africa. BMC Pediatr. 2019;19(1):320.

8. Schmithausen RM, Sib E, Exner M, Hack S, Rosing C, Ciorba P, et al. The washing machine as a reservoir for transmission of extended spectrum beta-lactamase (CTX-M-15)-producing Klebsiella oxytoca ST201 in newborns. Appl Environ Microbiol. 2019.

9. Voigt AM, Faerber HA, Wilbring G, Skutlarek D, Felder C, Mahn R, et al. The occurrence of antimicrobial substances in toilet, sink and shower drainpipes of clinical units: a neglected source of antibiotic residues. Int J Hyg Environ Health. 2019;222(3):455-67.

10. Pendleton N, Cheesbrough JS, Walshaw MJ, Hind CR. Bacterial colonisation of humidifier attachments on oxygen concentrators prescribed for long term oxygen therapy: a district review. Thorax. 1991;46(4):257-8.

11. Sehulster L, Chinn RY, Cdc, Hicpac. Guidelines for environmental infection control in health-care facilities. Recommendations of CDC and the Healthcare Infection Control Practices Advisory Committee (HICPAC). MMWR Recomm Rep. 2003;52(RR-10):1-42.

12. Lemmen SW, Hafner H, Zolldann D, Stanzel S, Lutticken R. Distribution of multi-resistant Gram-negative versus Gram-positive bacteria in the hospital inanimate environment. J Hosp Infect. 2004;56(3):191-7.

13. Rawlinson S, Ciric L, Cloutman-Green E. How to carry out microbiological sampling of healthcare environment surfaces? A review of current evidence. J Hosp Infect. 2019;103(4):363-74.

14. Nakamura $K$, Kaneko M, Abe Y, Yamamoto N, Mori H, Yoshida A, et al. Outbreak of extended-spectrum beta-lactamase-producing Escherichia coli transmitted through breast milk sharing in a neonatal intensive care unit. J Hosp Infect. 2016;92(1):42-6.

15. Cadot L, Bruguiere H, Jumas-Bilak E, Didelot MN, Masnou A, de Barry G, et al. Extended spectrum beta-lactamase-producing Klebsiella pneumoniae outbreak reveals incubators as pathogen reservoir in neonatal care center. Eur J Pediatr. 2019;178(4):505-13.

16. WHO Guidelines on Hand Hygiene in Health Care: A Summary. Accessed 23 Nov, 2021 at: https://www.who.int/gpsc/5may/tools/who_guidelineshandhygiene summary.pdf 2009.

17. Kotay S, Chai W, Guilford W, Barry K, Mathers AJ. Spread from the Sink to the Patient: In Situ Study Using Green Fluorescent Protein (GFP)-Expressing Escherichia coli To Model Bacterial Dispersion from Hand-Washing Sink-Trap Reservoirs. Appl Environ Microbiol. 2017;83(8).

18. Roux D, Aubier B, Cochard H, Quentin R, van der Mee-Marquet N, Centre HAIPGotRdHd. Contaminated sinks in intensive care units: an underestimated source of extended-spectrum beta-lactamaseproducing Enterobacteriaceae in the patient environment. J Hosp Infect. 2013:85(2):106-11.

19. Hopman J, Tostmann A, Wertheim H, Bos M, Kolwijck E, Akkermans R, et al. Reduced rate of intensive care unit acquired gram-negative bacilli after removal of sinks and introduction of "water-free" patient care. Antimicrob Resist Infect Control. 2017:6:59.

20. CDC: Best Practices for Environmental Cleaning in Healthcare Facilities: in Resource-Limited Settings, accessed 7 June, 2021. https://www.cdc.gov/ hai/pdfs/resource-limited/environmental-cleaning-RLS-H.pdf.
21. World Health Organisation, "Safe preparation, storage and handling of powdered infant formula: Guidelines", 2007. Accessed 26 July, 2021. https://www.who.int/foodsafety/publications/micro/pif_guidelines.pdf.

22. Cotton MF, Wasserman E, Pieper CH, Theron DC, van Tubbergh D, Campbell $\mathrm{G}$, et al. Invasive disease due to extended spectrum beta-lactamaseproducing Klebsiella pneumoniae in a neonatal unit: the possible role of cockroaches. J Hosp Infect. 2000;44(1):13-7.

23. Tufa TB, Fuchs A, Wienemann T, Eggers Y, Abdissa S, Schneider M, et al. Carriage of ESBL-producing Gram-negative bacteria by flies captured in a hospital and its suburban surroundings in Ethiopia. Antimicrob Resist Infect Control. 2020;9(1):175.

24. Rao M, Laidlaw A, Li L, Young K, Tamber S. Isolation of third generation cephalosporin resistant Enterobacteriaceae from retail meats and detection of extended spectrum beta-lactamase activity. J Microbiol Methods. 2021;189:106314

25. Livingston SH, Cadnum JL, Gestrich S, Jencson AL, Donskey CJ. A novel sink drain cover prevents dispersal of microorganisms from contaminated sink drains. Infect Control Hosp Epidemiol. 2018;39(10):1254-6.

26. Efstathiou P, Anagnostakou M, Kouskouni E, et al. O068: Implementation of antimicrobial copper in neonatal intensive care unit (NICU). Antimicrob Resist Infect Control. 2013;2(Suppl 1):O68. Published 2013 Jun 20. doi:https://doi.org/10.1186/2047-2994-2-S1-068.

\section{Publisher's Note}

Springer Nature remains neutral with regard to jurisdictional claims in published maps and institutional affiliations.

Ready to submit your research? Choose BMC and benefit from

- fast, convenient online submission

- thorough peer review by experienced researchers in your field

- rapid publication on acceptance

- support for research data, including large and complex data types

- gold Open Access which fosters wider collaboration and increased citations

- maximum visibility for your research: over $100 \mathrm{M}$ website views per year

At BMC, research is always in progress.

Learn more biomedcentral.com/submissions 